\title{
Effects of plant density on yield and quality of watermelon (Citrullus lanatus thunb) under Gezira conditions, Sudan
}

\author{
Adlan M. A. Adlan* and Asim F. Abu-Sarra \\ Agricultural Research Corporation, Horticultural Research Centre, Wad Medani, Sudan.
}

Accepted 6 November, 2017

\begin{abstract}
An experiment was conducted at the Gezira Research Farm in the winter season of 2009/10 and the kharif season of 2010 to study the effects of plant density on watermelon yield and quality. Treatments consisted of three intra-row spacing of 50,70 and $90 \mathrm{~cm}$ and three number of plants per hole; 1,2 and 3 . Treatments were arranged in randomized complete block design with three replicates. Results indicated significant differences among treatments in number of branches plant $^{-1}$ in both seasons. However no significant differences were observed in vine length in both seasons and number of leaves/plant in the winter season, but in kharif season significant differences was observed in number of leaves/plant. Results of yield components indicated no significant differences among treatments in number of fruits per hectare. There were highly significant differences in marketable fruits yield in both seasons. Also, there were significant and highly significant differences in total soluble solids in the winter and kharif seasons, respectively. The results indicated that $70 \mathrm{~cm}$ intra-row spacing with one plant/hole gave the optimum plant density for watermelon, since it resulted in optimum growth and the highest marketable yield and best quality.
\end{abstract}

Keywords: Gezira, kharif, plant density, watermelon, yield and quality, intra-row spacing.

*Corresponding author. E-mail: adlan.m.a.2015@gmail.com.

\section{INTRODUCTION}

Watermelon (Citrullus lanatus (Thunb.) Mansfed) is one of the widely cultivated crops in the world (Huh et al., 2008). In the Sudan watermelon produced as an irrigated crop along the river banks of central and northern parts of the country.

Inter-row spacing and intra-row spacing is an important agronomic attribute, since it is believed to have effects on light interception which affects the photosynthetic process. In watermelon, increasing planting density decreases the number of fruits per plant, but individual fruit size is mostly unaffected (Duthie et al., 1999).

Watermelon yield and quality in Gezira are low. Marketable yield is usually around 9 tons $\mathrm{ha}^{-1}$ and unmarketable fruits exceed 3 tons ha ${ }^{-1}$. Many factors contribute to this situation such as fertilizer application and plant density.

No studies on plant population of watermelon were conducted in the Sudan. Farmers usually sow numerous seeds per hole at various intra-row spacing ranging between 50 and $150 \mathrm{~cm}$ and inter-row spacing of 250, 300 or $350 \mathrm{~cm}$. The crop is thinned to $1-2$ plants/hole after one month after sowing. This accounts for 20 to 27 thousand plants per hectare.

The objective of this study was to evaluate the response of watermelon to intra-row spacing and number of plants/hole.

\section{MATERIALS AND METHODS}

The experiment was carried out in the Vegetable Research Farm of the Gezira Research Station at Wad Medani Sudan $\left(14^{\circ} 6^{\prime} \mathrm{N}\right.$ and $33^{\circ} 38^{\prime} \mathrm{E}, 400 \mathrm{~m}$ asl), soil of the farm belongs to the heavy cracking clay plains of central Sudan, during the winter season of 2009/10 and the autumn of 2010 to study the effects of intra-row spacing and number of plants per hole on yield and quality of irrigated watermelons under Gezira conditions. Treatments consisted of three intra-row spacing 50, 70 and $90 \mathrm{~cm}$ and three number of 
plants/hole 1, 2 and 3 (Table 1), the seed were on $19^{\text {th }}$ October $2019 / 10$ and $24^{\text {th }}$ July 2010 , treatments were arranged in randomize complete block design with 3 replicates. The soil was first cleaned and then disc ploughed, harrowed, leveled and then divided into raised beds $3 \mathrm{~m}$ wide. Experimental units were formed to include two beds $8 \mathrm{~m}$ long $\left(48 \mathrm{~m}^{2}\right)$. Urea $(46 \% \mathrm{~N})$ was applied at the rate of $86 \mathrm{~kg} \mathrm{ha}^{-1}$ in two equal doses at 4 and 7 weeks after sowing, other cultural practices were done as recommended by ARC. The data consisted of growth, yield and quality parameters of watermelon. The data collected from the experiment were evaluated by analysis of variance procedure using the GenStat computer package (Buysse et al., 2004).

\section{RESULTS}

The results shown in Table 2, Figures 1 and 2 indicated no significant effects of intra-row spacing and number of plants/hole or their interaction on vine length, number of branches/plant and number of leaves/plant in both seasons.

No significant effects were detected for the intra-row spacing, number of plants/ha and their interaction on the number of marketable fruits/ha in the both seasons; except the main effect of the number of plants/hole in the kharif season which illustrated very highly significant effect (Table 3). The highest number of marketable fruits/ha in the kharif season was obtained with a single plant per hole.

The effects of intra-row spacing, number of plants/hole and their interaction, in the winter and kharif season, on marketable watermelon yield are show in Table 4 . Very highly and highly significant differences were observed for the main effects and interactions of the two factors in both seasons; except for the main effect of the intra-row spacing in the kharif season. The highest marketable yield was obtained from intra-row spacing of $70 \mathrm{~cm}$ and one plant/hole in both seasons. The lowest yield in the winter season was scored by the intra-row spacing of 50 $\mathrm{cm}$ intra-row spacing with three plants/hole and 70 and $90 \mathrm{~cm}$ intra-row spacing with two plants/hole in the kharif season.

Concerning watermelon fruits quality no significant effects were detected for the main effects of intra-row spacing or the interaction between the intra-row spacing and the number of plants/hole for watermelon fruits quality as measured by percentage total soluble solids (TSS), whereas, the main effect of the number of plants/hole was significant on (TSS) in the two seasons. The highest TSS was obtained when one plant is kept/hole in both seasons (Figure 3).

Table 1. Factorial combinations of three intra-row spacing and three numbers of plants/hole and their projected plant populations/ha.

\begin{tabular}{cccc}
\hline Treatment number & Intra-row spacing $\mathbf{( c m )}$ & Number of plants/hole & Plant population/ha $(\times \mathbf{1 0 0 0})$ \\
\hline 1 & 50 & 1 & 11.7 \\
2 & 50 & 2 & 23.3 \\
3 & 50 & 3 & 35.0 \\
4 & 70 & 1 & 8.3 \\
5 & 70 & 2 & 16.7 \\
6 & 70 & 3 & 25.0 \\
7 & 90 & 1 & 6.7 \\
8 & 90 & 2 & 13.3 \\
9 & 90 & 3 & 20.0 \\
\hline
\end{tabular}

\section{DISCUSSION}

Results of plant growth obtained from winter and kharif seasons were in agreement with those reported by Dean (2004), who found no influence of intra-row spacing on growth parameters of muskmelon.

In both seasons, the number of marketable fruits/ha produced by one plant/hole increased with an increase in plant spacing. This result was in agreement with those reported by Maynard and Scott (1998) who stated that in the wider spaced plants, the area allotted for development of the single plant is larger and hence provide a possibility for more lush growth and development of fruit bearing branches. For high densities, plants compete with each other for nutrients, water and light and, therefore, develop less fruiting branches.

In both seasons, the intra-row spacing of $70 \mathrm{~cm}$ with one plant/hole (8.3 thousand plants/ha) gave the highest marketable yield and total soluble solids (TSS) followed by the $90 \mathrm{~cm}$ and one plant/hole (6.7 thousand plants/ha) and then the $50 \mathrm{~cm}$ and one plant/hole $(11.7$ thousand plants/ha). Similar observations were reported by Duthie et al. (1999) who stated that watermelon yield per unit area tends to increase with plant density up to a certain level and then decrease due to interplant competition.

\section{Conclusion}

Highly significant effects of intra-row spacing and number 
Table 2. Effect of intra-row spacing and number of plants/hole $(P)$ on plant length of watermelon.

\begin{tabular}{|c|c|c|c|c|c|c|c|c|}
\hline \multirow{3}{*}{ Intra-row spacing (cm) } & \multicolumn{8}{|c|}{ Plant length (cm) } \\
\hline & \multicolumn{4}{|c|}{ Winter season $2009 / 10$} & \multicolumn{4}{|c|}{ Kharif season 2010} \\
\hline & $P 1^{\Omega}$ & P2 & P3 & mean & P1 & P2 & P3 & Mean \\
\hline 70 & 148 & 120 & 142 & 142 & 151 & 123 & 162 & 145 \\
\hline 90 & 159 & 115 & 133 & 133 & 142 & 118 & 126 & 129 \\
\hline mean & 151 & 134 & 143 & & 155 & 145 & 129 & \\
\hline Statistics & \multicolumn{2}{|c|}{ Prob. } & \multicolumn{2}{|r|}{$\operatorname{SE}( \pm)$} & \multicolumn{2}{|c|}{ Statistics } & Prob. & $\operatorname{SE}( \pm)$ \\
\hline Intra-row (S) & \multicolumn{2}{|c|}{0.323} & \multicolumn{2}{|r|}{-} & \multicolumn{2}{|c|}{ Intra-row (S) } & 0.102 & - \\
\hline Plants/hole (P) & \multicolumn{2}{|c|}{0.414} & \multicolumn{2}{|r|}{-} & \multicolumn{2}{|c|}{ Plants/hole (P) } & 0.672 & - \\
\hline$S \times P$ & \multicolumn{2}{|c|}{0.161} & & - & \multicolumn{2}{|c|}{$S \times P$} & 0.234 & - \\
\hline
\end{tabular}

${ }^{\Omega} \mathrm{P} 1$ = one plant/hole, $\mathrm{P} 2$ = two plants $/$ hole, $\mathrm{P} 3$ = three plants $/$ hole.

winter season

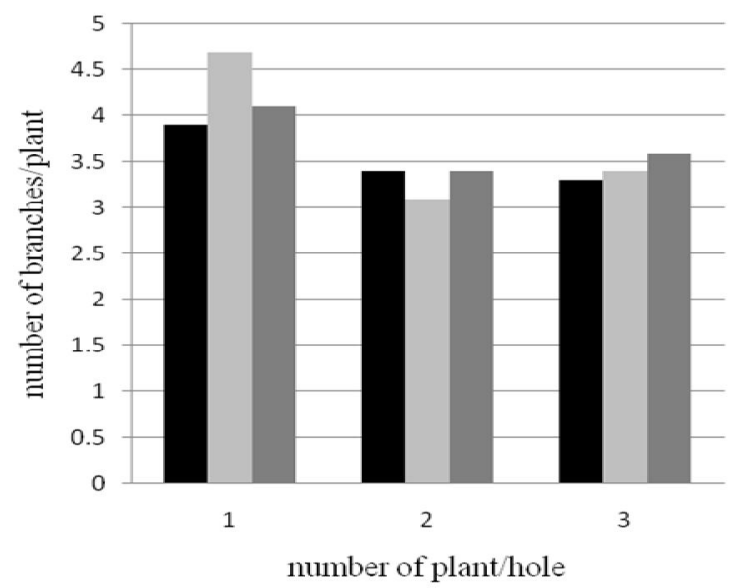

kharitseason

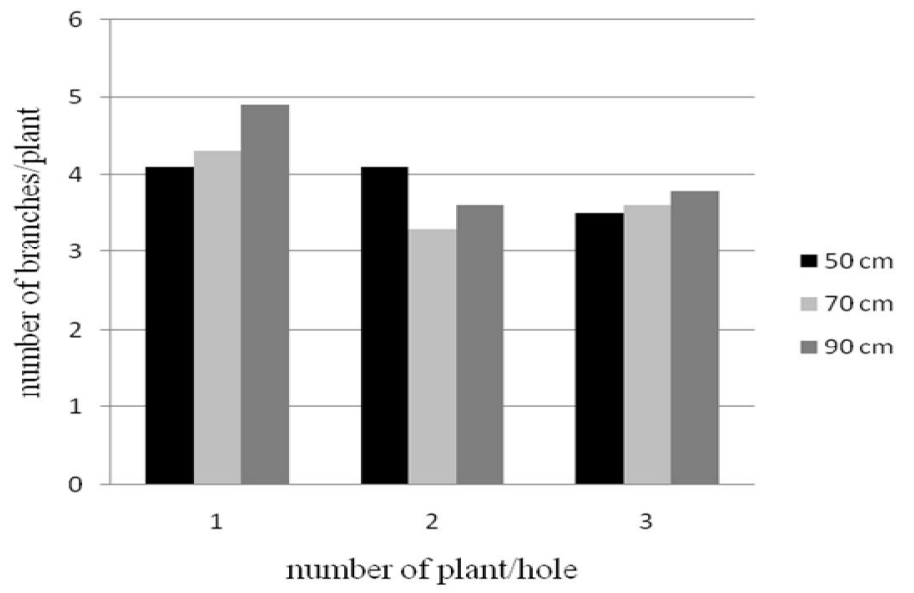

Figure 1. Effect of number of plant/hole on number of branches/plant of watermelon.
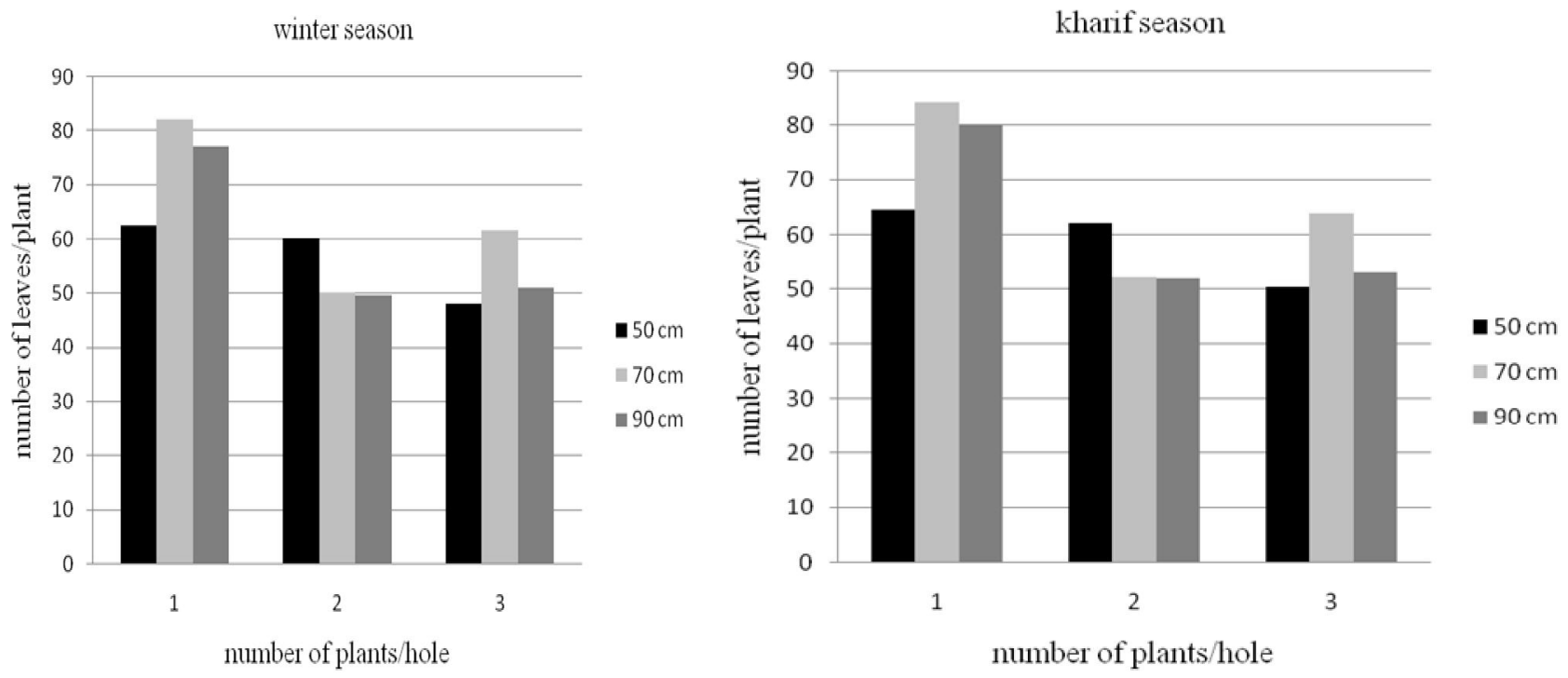

Figure 2. Effect of number of plants/hole on number of leaves/plant of watermelon. 
Table 3. Effect of intra-row spacing and number of plants/hole $(P)$ on number of marketable fruits/ha of watermelon.

\begin{tabular}{|c|c|c|c|c|c|c|c|c|}
\hline \multirow{3}{*}{ Intra-row spacing (cm) } & \multicolumn{8}{|c|}{ Number of fruits/ha $(\times 1000)$} \\
\hline & \multicolumn{4}{|c|}{ Winter season $2009 / 10$} & \multicolumn{4}{|c|}{ Kharif season 2010} \\
\hline & $P 1^{\Omega}$ & P2 & P3 & Mean & P1 & P2 & P3 & Mean \\
\hline 50 & 4.31 & 4.58 & 6.25 & 5.05 & 5.55 & 5.42 & 5.83 & 5.60 \\
\hline 70 & 5.28 & 4.72 & 5.42 & 5.14 & 5.83 & 5.00 & 5.42 & 5.42 \\
\hline 90 & 6.25 & 5.14 & 5.00 & 5.46 & 5.83 & 4.86 & 5.69 & 5.46 \\
\hline mean & 5.28 & 4.81 & 5.56 & & 5.74 & 5.09 & 5.65 & \\
\hline CV (\%) & \multicolumn{4}{|c|}{14.5} & \multicolumn{4}{|c|}{12.8} \\
\hline Statistics & \multicolumn{2}{|c|}{ Prob. } & \multicolumn{2}{|r|}{$\operatorname{SE}( \pm)$} & \multicolumn{2}{|c|}{ Statistics } & Prob. & $\operatorname{SE}( \pm)$ \\
\hline Intra-row (S) & \multicolumn{2}{|c|}{0.489} & \multicolumn{2}{|r|}{-} & \multicolumn{2}{|c|}{ Intra-row (S) } & 0.70 & - \\
\hline Plants/hole (P) & \multicolumn{2}{|c|}{0.144} & \multicolumn{2}{|r|}{-} & \multicolumn{2}{|c|}{ Plants/hole (P) } & 0.02 & 0.150 \\
\hline$S \times P$ & \multicolumn{2}{|c|}{0.35} & & - & \multicolumn{2}{|c|}{$S \times P$} & 0.466 & - \\
\hline
\end{tabular}

${ }^{\Omega} \mathrm{P} 1=$ one plant/hole, $\mathrm{P} 2=$ two plants/hole, $\mathrm{P} 3=$ three plants/hole.

Table 4. Effect of intra-row spacing and number of plants/hole $(P)^{\Omega}$ on marketable yield of watermelon at Gezira Research Station.

\begin{tabular}{|c|c|c|c|c|c|c|c|c|}
\hline \multirow{3}{*}{ Intra-row spacing (cm) } & \multicolumn{8}{|c|}{ Marketable yield (ton $\mathrm{ha}^{-1}$ ) } \\
\hline & \multicolumn{4}{|c|}{ Winter season $2009 / 10$} & \multicolumn{4}{|c|}{ Kharif season 2010} \\
\hline & $\mathrm{P1}^{\Omega}$ & P2 & P3 & Mean & P1 & P2 & P3 & Mean \\
\hline 50 & 11.2 & 11.0 & 9.5 & 10.5 & 11.2 & 11.0 & 10.7 & 11.0 \\
\hline 70 & 12.0 & 9.7 & 10.5 & 10.7 & 12.1 & 10.3 & 10.7 & 11.0 \\
\hline 90 & 11.7 & 10.2 & 10.7 & 10.9 & 11.2 & 10.3 & 10.7 & 10.8 \\
\hline mean & 11.6 & 10.3 & 10.2 & & 11.5 & 10.5 & 10.7 & \\
\hline CV (\%) & \multicolumn{4}{|c|}{5} & \multicolumn{4}{|c|}{3} \\
\hline Statistics & \multicolumn{2}{|c|}{ Prob. } & \multicolumn{2}{|c|}{$\operatorname{SE}( \pm)$} & \multicolumn{2}{|c|}{ Statistics } & Prob. & $\operatorname{SE}( \pm)$ \\
\hline Intra-row (S) & \multicolumn{2}{|c|}{$<0.001$} & \multicolumn{2}{|c|}{0.019} & \multicolumn{2}{|c|}{ Intra-row (S) } & 0.231 & - \\
\hline Plants/hole (P) & \multicolumn{2}{|c|}{$<0.001$} & \multicolumn{2}{|c|}{0.019} & \multicolumn{2}{|c|}{ Plants/hole $(\mathrm{P})$} & $<0.001$ & 0.11 \\
\hline$S \times P$ & \multicolumn{2}{|c|}{$<0.001$} & \multicolumn{2}{|c|}{0.032} & $S \times P$ & & 0.004 & 0.19 \\
\hline
\end{tabular}

${ }^{\Omega} \mathrm{P} 1$ = one plant/hole, $\mathrm{P} 2$ = two plants/hole, $\mathrm{P} 3=$ three plants/hole.
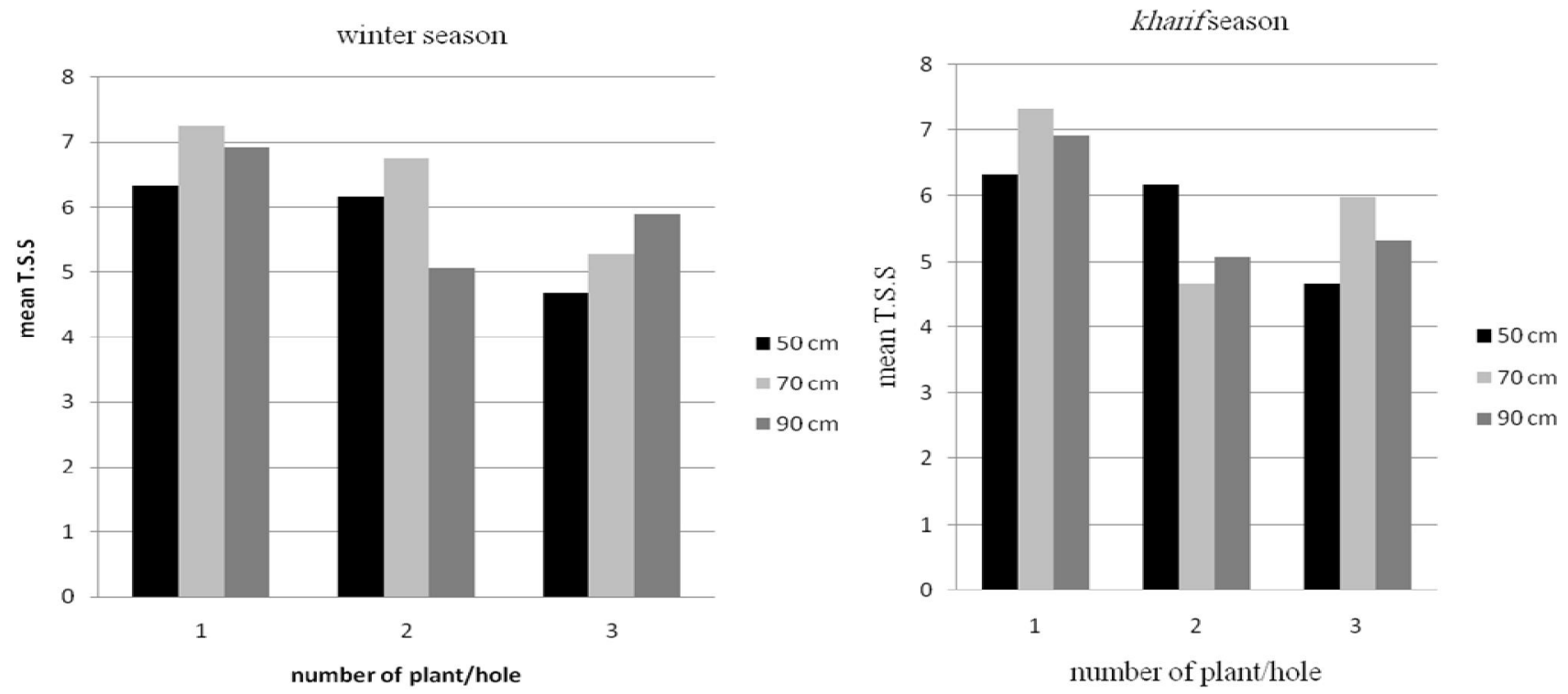

Figure 3. Effect of no. of plants/hole on TSS of watermelon. 
of plant/hole were detected on the weight of marketable fruits and the highest weight was obtained from $70 \mathrm{~cm}$ intra-row spacing with one plant/hole in both seasons.

Watermelon fruit quality was highly affected by number of plants/hole and the sweetest fruits (high TSS \%) were obtained from keeping one plant/hole in both seasons.

According to the results of this study, the intra-row spacing $70 \mathrm{~cm}$ with one plant/hole can be suggested as the optimum planting method to produce best quality watermelon with high yield in the Gezira area, Sudan.

\section{REFERENCES}

Buysse W, Stern R, Coe R, 2004. Gen Stat Discovery Edition for Everyday Use. ICRAF Nairobi, Kenya. pp. 114.

Dean B, 2004. Effect of Intra-row Spacing on Muskmelon Growth and Yield. Institute for Agriculture and Tourism, Carla Huguesa 8, 52440 Porec, Croatia.

Duthie JA, Shrefler JW, Roberts BW, Edelson JV, 1999. Plant density dependent variation in marketable yield, fruit biomass, and marketable fraction in watermelon. Crop Sci, 39: 406-412.

Huh YC, Solmaz I, Sari N, 2008. Morphological Characterization of Korean and Turkish Watermelon Germplasm. Proceedings of the IXth EUCARPIA meeting on genetics and breeding of Cucurbitaceae. May 2008 (Ed. Pitrat M.), INRA, Avignon (France). pp: 21-24.

Maynard ET, Scott WD, 1998. Plant spacing affects yield of "Superstar" muskmelon. Horticult Sci, 33(1): 52-54.
Citation: Adlan AMA, Abu-Sarra AF, 2018. Effects of plant density on yield and quality of watermelon (Citrullus lanatus thunb) under Gezira conditions, Sudan. Net J Agric Sci, 6(1): 1-5. 